\title{
The relative age effect on physical fitness in preschool children
}

\author{
Rocío Cupeiro ${ }^{\mathrm{a}}$, Miguel A. Rojo-Tirado ${ }^{\mathrm{a} *}$, Cristina Cadenas-Sánchez ${ }^{\mathrm{b}, \mathrm{c}}$, Enrique G. Artero ${ }^{\mathrm{d}, \mathrm{e}}$, Ana B. Peinado \\ Idoia Labayenc, Cecilia Doradof,g, Natalia M. Arias-Palencia ${ }^{\text {hi, }}$, Diego Moliner-Urdiales ${ }^{j}$, Josep Vidal-Contik, \\ Julio Conde-Caveda $\mathbb{D D}^{1, m}$, José Mora-Gonzalez ${ }^{\mathrm{b}, \mathrm{n}}$, Germán Vicente-Rodríguez ${ }^{\circ}{ }^{\circ}$, Pedro J. Benito $\mathbb{D}^{\mathrm{a}}$ and on behalf of \\ the PREFIT project group
}

aLFE Research Group, Department of Health and Human Performance, Faculty of Physical Activity and Sport Sciences (INEF), Universidad Politécnica De Madrid, Madrid, Spain; 'bPROFITH "Promoting FITness and Health through Physical Activity" Research Group, Sport and Health University Research Institute (Imuds), Department of Physical Education and Sports, Faculty of Sport Sciences, University of Granada, Granada, Spain; 'Institute for Innovation \& Sustainable Development in Food Chain (IS-FOOD), Public University of Navarra, Pamplona, Spain;

10 dDepartment of Education, Faculty of Education Sciences, University of Almería, Almería, Spain; eSPORT Research Group (CTS-1024), CERNEP Research Center, University of Almería, Almería, Spain; 'Department of Physical Education, University of Las Palmas De Gran Canaria, Canary

Q4 Islands, Spain; ${ }^{9}$ Research Institute of Biomedical and Health Sciences (IUIBS), Las Palmas De Gran Canaria, Spain; ${ }^{h} H e a l t h$ and Social Research Center, Universidad De Castilla- La Mancha, Cuenca, Spain; 'School of Education, Universidad De Castilla- La Mancha, Cuenca, Spain; 'LIFE Research Group, Faculty of Humanities and Social Sciences, University Jaume I, Castellón, Spain; kPhysical Activity and Sport Sciences

15 Research Group, Universitat De Les Illes Balears, Spain; 'Department of Physical Education, Faculty of Education Sciences, University of Cádiz, Puerto Real, Spain; ${ }^{m}$ Biomedical Research and Innovation Institute of Cádiz (Inibica), Cádiz, Spain; ${ }^{n}$ College of Health and Human Services, University of North Carolina at Charlotte, Charlotte, NC, USA; ${ }^{\circ}$ GENUD (Growth, Exercise, NUtrition and Development) Research Group, Instituto Agroalimentario De Aragón -IA2- (Cita-universidad De Zaragoza), Centro De Investigación Biomédica En Red De Fisiopatología De La Obesidad Y Nutrición (Ciberobn), Faculty of Health and Sport Science (FCSD, Huesca, Spain), Department of Physiatry and Nursing, University

20 of Zaragoza, Zaragoza, Spain

\section{ABSTRACT}

The aim of the present study was to investigate the existence of a relative age effect (RAE) on physical fitness of preschoolers. Anthropometry and physical fitness were assessed in 3147 children (3-5 years old) using the PREFIT battery. Based on the birth year, participants were divided into 3year, groups (3-, 4- and 5-years). Within each year group, 4quarter groups were created: quarter 1, preschoolers born from January to March; quarter 2, from April to June; quarter 3, from July to September; quarter 4, from October to December. The MANCOVA analysis revealed a main effect of year group (Wilks' $\lambda=0.383 ; \mathrm{F}_{10,5996}=369.64 ; \mathrm{p}<0.001, \eta_{\mathrm{p}}{ }^{2}=0.381$ ) and of quarter (Wilks' $\lambda=0.874 ; F_{15,8276.6}=27.67 ; p<0.001 ; \eta_{p}{ }^{2}=0.044$ ) over the whole battery of tests. To the best of our knowledge, this is the first study to report the existence of RAE at the preschool stage. In general, performance improved as the relative age increased (i.e., those born in quarter 1 performed better than those in the other quarters). Individualization strategies should be addressed within the same academic year not only in elementary or secondary years but also in preschoolers.

\section{ARTICLE HISTORY}

Accepted 4 March 2020

KEYWORDS

Muscular strength; balance; speed-agility; cardiorespiratory fitness; preschoolers; RAE

\section{Introduction}

In most elementary or primary schools, a cut-off date for grouping the children according to their age is used. Therefore, almost a 1-year difference in chronological age could be found between the eldest and youngest children within the same class. This difference in birthdates has been reported to have an effect on the cognitive achievement and motor skill proficiency of the younger versus the elder, in children and adolescents (Roberts \& Fairclough, 2012). Numerous studies from the $80 \mathrm{~s}$ until the present have consistently found lower attainments for the younger members in both academic/cognitive (Bedard \& Dhuey, 2006; Gledhill et al., 2002; Wienen et al., 2018) and physical education/sports performances (Andronikos et al., 2016; Baker et al., 2009; Bell \& Daniels, 1990; Birch et al., 2016; Brazo-Sayavera et al., 2017).
The "relative age effect" (RAE) is the influence of the difference in birthdates among the members of a given age cohort (Bell \& Daniels, 1990; Roberts \& Fairclough, 2012), and it seems to exists in part due to the different maturity status present within the members of the cohort, although the complexity of RAE is larger and other aspects beyond maturation may play an important role, like social or behavioural factors (also known as task and environmental constraints) (Hancock et al., 2013; Wattie et al., 2015). Specifically for physical education and sports participation, this effect can have important implications regarding biased assessment and selection (Brazo-Sayavera et al., 2017; Haycraft et al., 2018), reinforcing the proficiency of older more mature individuals (Cobley et al., 2008; Furley \& Memmert, 2016). Thus, RAE may handicap younger children not only in the sport context but also during physical education classes, where most of the contents and evaluation process are

CONTACT Pedro J. Benito pedroj.benito@upm.es Department of Health and Human Performance, Faculty of Physical Activity and Sport Sciences-INEF, Universidad Politécnica De Madrid, C/Martín Fierro 7, Madrid 28040, España

*These authors contributed equally to this work

(4) Supplemental data for this article can be accessed here.

○ 2020 Informa UK Limited, trading as Taylor \& Francis Group 
65 based on physical attainment. The existence of RAE in fitnessrelated tasks (i.e., physical education, sports performances, fundamental skill proficiency or physical literacy) has been found in children (Birch et al., 2016; Müller et al., 2015; Nakata et al., 2017; Roberts et al., 2012) as well as in adolescents (Cobley et

70 al., 2009; Dalen et al., 2017; Kearney et al., 2018; Nakata et al., 2017; Roberts et al., 2012; Sandercock et al., 2014), although the clinical relevance of this effect, evidenced through the value of the effect size, has sometimes been questioned (Dutil et al., 2018). Therefore, this effect seems to exist throughout all the educational period. Furthermore, when RAE investigation is made within the context of sports, the selection process present might compromise the interpretation of results about the mechanisms underlying presents in RAE. Investigating RAE in schools eliminates any kind of selection, making it a more suitable setting for studying this topic.

However, to the best of our knowledge, no study has investigated the existence of RAE on fitness status in preschoolers (3-5 years), a stage at which fitness could be as important as in older children (Cadenas-Sanchez, Martinez-Tellez et al., 2016; Smith et al., 2014). Teachers should be aware of the existence of RAE and its consequences (Bell \& Daniels, 1990), even in these ages, in order to adapt their interventions and assessments. No study had described the fitness status in these initial years of school until recently, mainly because of the lack of reliable and valid battery tests for these age levels (Ortega et al., 2015). In this context, PREFIT (Assessing FITness levels in PREschoolers) battery has been proven to be a feasible and reliable test (Cadenas-Sanchez, Martinez-Tellez et al., 2016), which allows obtaining physical fitness (cardiovascular, strength and motor skills) data in children at the preschool stage.

Therefore, the aim of the present study was to investigate the existence of RAE on physical fitness of preschool children from multiple regions across Spain. It was hypothesized that fitness performance measured by the PREFIT battery, would be higher in preschoolers born in the first quarters of the year compared to those born in the last quartile of the same year.

\section{Methods}

\section{Participants and study design}

This study belongs to the PREFIT Project (www.profith.ugr.es/ prefit), whose complete description can be found elsewhere (Cadenas-Sanchez, Martinez-Tellez et al., 2016). A total of 4338 preschoolers (3-5 years) and their parents were invited to participate in the PREFIT Project. Finally, 3198 parents and/ or guardians agreed to participate in the study (participation rate: $73.7 \%$ ) by signing an informed consent. Among them, 19 children were excluded after the assessments (i.e., they presented a motor or cerebral disease that limited the test performance reported by the school teachers, they cried during most tests, they had a cough and mucus, or they did not understand the instructions of the tests correctly). Therefore, 3179 preschool children participated in the PREFIT Project, from 10 different cities/towns across Spain (i.e., Almería, Cádiz, Castellón de la Plana, Cuenca, Granada, Las Palmas de Gran Canaria, Madrid, Palma de Mallorca, Vitoria-Gasteiz, and Zaragoza), maintaining a balance between public and private schools in each city for a higher socio-economic diversity. Prior to the completion of the test battery, a questionnaire, which has already been shown to objectively measure physical fitness in preschool children, was administered to parents to determine their child's level of physical activity (Palou et al., 2019). In this questionnaire, as an indirect measure of the physical activity level of the children, parents were asked to classify their children's physical activity level, excluding school time, in very low, low, average, high, or very high. Then, children took part in physical fitness and anthropometry evaluations; researchers excluded 32 preschoolers for not declaring their birthdates or for being in a course not corresponding with their age. As a result, a total of 3147 children (3-years old [480 boys and 441 girls], 4-years old [593 boys and 523 girls] and 5-years old [582 boys and 528 girls]) were included in this study (4.6 \pm 0.9 years old; 1655 boys, $52.6 \%$ ). Data collection took place from January 2014 to November 2015. The study protocol passed the Review Committee for Research Involving Human Subjects evaluation from the U.G. (reference number: 845) and adheres to the Helsinki Declaration of 1961, revised in Fortaleza (Brazil) in 2013.

The PREFIT battery (Ortega et al., 2015), which has been proved to be feasible and reliable in preschoolers (CadenasSanchez, Martinez-Tellez et al., 2016), comprises the following tests: weight and height to assess anthropometry, upper-body muscular strength (handgrip strength test), lower limb strength (standing long jump test), balance (one-leg stance test), speedagility ( $4 \times 10 \mathrm{~m}$ shuttle run test) and cardiorespiratory fitness (PREFIT $20 \mathrm{~m}$ shuttle run test). Each child was assessed individually in a school setting by trained evaluators using standardized equipment and following the same methodology in all the participating centres. Detailed information can be found elsewhere (Cadenas-Sanchez, Martinez-Tellez et al., 2016).

\section{Procedures}

Before tests were applied, we performed a warm-up (3-5 min) that included running and jumping games. Tests were administered individually and in randomized order, except the PREFIT $20 \mathrm{~m}$ shuttle run test that was performed in the last place and in small groups of 4-8 students. In order to make the tests more attractive we created two different fairy tales that were explained to the children before and during the assessment (Cadenas-Sanchez, Martinez-Tellez et al., 2016).

Weight $(\mathrm{kg})$ and height $(\mathrm{cm})$ were assessed without shoes and wearing light clothes. Weight was measured to the nearest $0.1 \mathrm{~kg}$ with an electronic scale (SECA 213, Hamburg, Germany) and height was assessed to the nearest $0.1 \mathrm{~cm}$ with a stadiometer (SECA 213, Hamburg, Germany). All measures were taken twice but not consecutively. The mean of the two measurements was used in the analyses.

Upper-body muscular strength was assessed by the handgrip strength test using an analog dynamometer (TKK 5001, Grip-A, Takei, Tokyo) (Cadenas-Sanchez, Sanchez-Delgado et al., 2016). Preschoolers squeezed gradually and continuously for at least 3 s, performing the test twice (alternately with both hands). The elbow was extended and avoiding contacting of any other part of the body with the dynamometer, except the hand being measured. The optimal grip span was fixed in 
$4.0 \mathrm{~cm}$ (Sanchez-Delgado et al., 2015). The best value of the two trials for each hand was chosen, and the average of both hands was used in the analyses $(\mathrm{kg})$.

Lower body muscular strength was assessed by the standing long jump test. This test consisted in jumping as far as possible with both feet at the same time and separated from each other approximately at the shoulder's width, remaining upright. Preschoolers performed 3jumps and the best of these attempts was used in the analyses $(\mathrm{cm})$. In order to help and guide the preschoolers to jump, we decided to draw footprints to help preschoolers to detect the take-off line and start jump.

Speed-agility was assessed by the $4 \times 10 \mathrm{~m}$ shuttle run test.

190 This test consisted in running and turning as fast as possible between 2parallel lines (10 $\mathrm{m}$ apart) drawn on the floor, covering $40 \mathrm{~m}$. To make this test simpler, zevaluators were positioned in both extremes and participants had to touch the evaluator hand (placed behind the line) and go back at maximum speed. The best of the 2 attempts was manually registered (using a stopwatch) by an experienced evaluator and was used in the analyses (i.e. lower time registered in seconds).

Static balance was assessed by the one-leg stance test. The child stood on one-leg still with the supporting leg on the floor and the free leg flexed at the knee, maintaining the balance position as long as possible. The chronometer was activated when the free leg leaves the floor. The test ended when the child could not maintain the required position. The test was done once with each leg and the mean (seconds) was used in the analysis.

Cardiorespiratory fitness was assessed using a modified version of the original $20 \mathrm{~m}$ shuttle run test (Léger et al., 1988): The PREFIT $20 \mathrm{~m}$ shuttle run test (Cadenas-Sánchez et al., 2014; Cadenas-Sanchez, Martinez-Tellez et al., 2016). Briefly, participants had to run back and forth between 2 lines $20 \mathrm{~m}$ apart with an audio signal. The test finished when the child failed to reach the end lines concurrent with the audio signal on 2 consecutive occasions or when the child stopped because of exhaustion. Bearing in mind the young age of the preschoolers, some adaptations from the original test were made by decreasing the initial speed (i.e. $6.5 \mathrm{~km} \mathrm{~h}^{-1}$ instead of the original $\left.8.5 \mathrm{~km} \mathrm{~h}^{-1}\right)$ and by having 2 evaluators running with a reduced group of children (e.g., 4-8 preschoolers of the same age) in order to provide an adequate pace and control. We recorded an audio track with the acoustic signals for the preschoolersadapted start speed at $6.5 \mathrm{~km}_{\lambda} \mathrm{h}^{-1}$ and increases of $0.5 \mathrm{~km}_{\lambda} \mathrm{h}^{-1}$ every minute. For a higher sensitivity, the test results were expressed as the number of laps completed, instead of minutes or stages as habitually. The feasibility, reliability and maximality of this test in preschoolers have been reported elsewhere (Cadenas-Sánchez et al., 2014; Cadenas-Sanchez, MartinezTellez et al., 2016).

In addition, the parents or legal tutors completed a socioeconomical and physical activity questionnaire where they reported the physical activity level of the children.

\section{Relative Age Effect (RAE)}

In Spain, the cut-off date to access the different academic courses is January 1 , and the start date of the academic course is the middle of September, so the children start school between the ages of 2.75 years ( 2 years and 9 months) and 3.75 years ( 3 years and 9 months). To determine the existence of $R A E$, birthdates of preschoolers were firstly recorded to reflect their birth quarter. Therefore, based on the birth year, participants were divided into 3 year groups: 3-year-old, 4-yearold and 5-year-old. Furthermore, within each year group and based on the birthdate, 4quarter groups were created. These groups were quarter 1, gathering children born from January to March; quarter 2, children from April to June; quarter 3, from July to September; and quarter 4, from October to December.

\section{Data analysis}

All statistical analyses were carried out using the SPSS software (SPSS v.24, IBM Corporation, New York, USA), with the significance level set at $p<0.05$. After checking for normality with Kolmogorov-Smirnov, tests, descriptive characteristics of the sample were calculated. Differences in all anthropometrics and fitness variables across quarter categories, year group (3-years, 4-years and 5-years) and sex were examined with multivariate analysis of covariance (MANCOVA) and univariate analysis of covariance (ANCOVA). The adjustment was performed to avoid the potential effect of the different measurement dates (ranging from January 2014 to November 2015). The cofactor was the difference in days between the date of evaluation, and the birthday date of the year of evaluation (for example, a child born on November 22, and measured on, May 7, would have a cofactor equal to -199). Effect size was calculated by partial etasquared $\left(\eta_{p}{ }^{2}\right)$ and small, moderate and large effect corresponded to values equal or greater than 0.001, 0.059, and 0.138 , respectively (Cohen, 1988). Prior to the main analysis and to avoid potential bias, an exploratory analysis of the physical activity level reported by parents were carried using an ANCOVA (quarter $x_{\lambda}$ sex $x_{\lambda}$ year group) adjusting by the same cofactor as above (i.e., the difference in days between the date of evaluation, and the birthday date of the year of evaluation), to examine any difference in physical activity level among quarters. In addition, the range of scores obtained in each fitness test was divided into 10, intervals (i.e., each interval covering one-tenth of the range), thus establishing 9cut-off points for each test in each year group. Interval number 1 included the lowest performance scores and interval number 10 the best performance scores. The number of cases between cut-off points was counted to observe the frequency of preschoolers in each interval.

\section{Results}

A total of 3147 healthy preschool children, aged 3-5 years, were evaluated in this study showing significant relative age effects when compared by quarter, within each year group analysed. The distribution of the participants was 921 children aged 3 years $(n=241$ [26.2\%], $n=241$ [26.2\%], $n=222$ [24.1\%] and $n=217$ [23.5\%], from quarters 1, 2, 3 and 4, respectively), 1116 children aged 4 years $(n=285$ [25.5\%], $\mathrm{n}=270$ [24.2\%], $\mathrm{n}=266$ [23.8\%] and $\mathrm{n}=295$ [26.4\%], from quarters 1, 2, 3 and 4, respectively) and 1110 children aged 5 years $(n=262$ [23.6\%], $n=289$ [26.0\%], $n=277$ [25.0\%] and

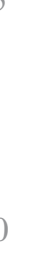


Table 1. Participants' characteristics $(N=3147)$.

\begin{tabular}{|c|c|c|c|c|c|c|c|c|c|}
\hline & & \multicolumn{2}{|c|}{$\begin{array}{c}\text { Quarter } 1 \\
\text { (Born from January to March) }\end{array}$} & \multicolumn{2}{|c|}{$\begin{array}{c}\text { Quarter } 2 \\
\text { (Born from April to June) }\end{array}$} & \multicolumn{2}{|c|}{$\begin{array}{c}\text { Quarter } 3 \\
\text { (Born from July to September) }\end{array}$} & \multicolumn{2}{|c|}{$\begin{array}{c}\text { Quarter } 4 \\
\text { (Born from October to December) }\end{array}$} \\
\hline & & Mean & SEM & Mean & SEM & Mean & SEM & Mean & SEM \\
\hline \multirow[t]{3}{*}{ Weight (kg) } & 3 years & 16.90 & 0.20 & 16.48 & 0.20 & $16.04^{a}$ & 0.21 & $15.56^{\mathrm{ab}}$ & 0.22 \\
\hline & 4 years & $19.47^{*}$ & 0.18 & $18.79^{*}$ & 0.19 & $18.22^{\mathrm{a} *}$ & 0.20 & $17.83^{\mathrm{ab}_{*}}$ & 0.18 \\
\hline & 5 years & $22.41^{* \#}$ & 0.19 & $21.83^{* \#}$ & 0.18 & $20.48^{a b_{* \#}}$ & 0.19 & $19.86^{\mathrm{ab} * \#}$ & 0.19 \\
\hline \multirow[t]{3}{*}{ Height (m) } & 3 years & 1.02 & 0.00 & $1.00^{\mathrm{a}}$ & 0.00 & $0.98^{\mathrm{ab}}$ & 0.00 & $0.96^{\mathrm{abc}}$ & 0.00 \\
\hline & 4 years & $1.09 *$ & 0.00 & $1.07^{\mathrm{a} *}$ & 0.00 & $1.05^{\mathrm{ab} *}$ & 0.00 & $1.04^{\mathrm{ab} *}$ & 0.00 \\
\hline & 5 years & $1.15^{* \#}$ & 0.00 & $1.14^{* \#}$ & 0.00 & $1.12^{\mathrm{ab} * \#}$ & 0.00 & $1.11^{\mathrm{abc} * \#}$ & 0.00 \\
\hline
\end{tabular}

$\mathrm{n}=282$ [25.4\%], from quarters 1, 2, 3 and 4, respectively). The exploratory analysis of the physical activity level reported by parents showed no differences among quarters and no interaction with quarter and sex or year group (data not shown). Descriptive characteristics of participants are shown in Table 1. The MANCOVA analysis revealed that there were no triple interaction (quarter $\times$ sex $\times$ year group) (Wilks' $\left.\lambda=0.993 ; F_{30,11,994}=0.66 ; p=0.92 ; \eta_{p}^{2}=0.001\right)$ and no double interaction between sex and quarter (Wilks' $\left.\lambda=0.993 ; F_{15,8276.6}=1.45 ; p=0.115, \eta_{p}{ }^{2}=0.002\right)$, but revealed

300 a main effect of year group (Wilks' $\lambda=0.383 ; F_{10,5996}=369.64$; $\mathrm{p}<0.001, \eta_{\mathrm{p}}{ }^{2}=0.381$ ) and a main effect of quarter (Wilks' $\lambda=0.874 ; F_{15,8276.6}=27.67 ; p<0.001 ; \eta_{p}{ }^{2}=0.044$ ) over the whole battery of tests. The univariate analysis showed a significant main effect of year group for weight $\left(F_{2,3000}=679.3\right.$; $\left.\mathrm{p}<0.001 ; \eta_{\mathrm{p}}{ }^{2}=0.312\right)$ and height $\left(\mathrm{F}_{2,3000}=2347.5 ; \mathrm{p}<0.001\right.$; $\eta_{\mathrm{p}}{ }^{2}=0.610$ ). In addition, a main effect of quarter was reported for these 2variables (weight: $F_{3,3000}=57.2 ; \mathrm{p}<0.001$; $\eta_{\mathrm{p}}{ }^{2}=0.054 ;$ Height: $\left.\mathrm{F}_{3,3000}=118 ; \mathrm{p}<0.001 ; \eta_{\mathrm{p}}{ }^{2}=0.158\right)$. The pairwise comparisons are shown in Table 1.

The main effect of year group was also observed for all fitness tests performed: handgrip strength test $\left(F_{2,3002}=1103.91\right.$; $\left.\mathrm{p}<0.001 ; \eta_{\mathrm{p}}{ }^{2}=0.424\right)$, standing long jump test $\left(F_{2,3002}=1184.97 ; p<0.001 ; \eta_{p}{ }^{2}=0.441\right), 4 \times 10 \mathrm{~m}$ shuttle run test $\left(F_{2,3002}=1348.05 ; p<0.001 ; \eta_{p}{ }^{2}=0.473\right)$, one-leg stance test $\left(F_{2,3002}=309.5 ; p<0.001 ; \eta_{p}{ }^{2}=0.171\right)$, and PREFIT $20 \mathrm{~m}$ shuttle run test $\left(F_{2,3002}=509.93 ; p<0.001 ; \eta_{p}{ }^{2}=0.254\right)$. Similarly, the main effect of quarter was significant for all fitness tests: handgrip strength test $\left(F_{3,3002}=76.16 ; p<0.001 ; \eta_{p}{ }^{2}=0.071\right)$, standing long jump test $\left(F_{3,3002}=17.63 ; p<0.001 ; \eta_{p}{ }^{2}=0.017\right)$, $4 \times 10 \mathrm{~m}$ shuttle run test $\left(\mathrm{F}_{3,3002}=94.22 ; \mathrm{p}<0.001 ; \eta_{\mathrm{p}}{ }^{2}=0.086\right)$, one-leg stance test $\left(F_{3,3002}=17.73 ; p<0.001 ; \eta_{p}{ }^{2}=0.017\right)$, and PREFIT $20 \mathrm{~m}$ shuttle run test $\left(\mathrm{F}_{3,3002}=17.96 ; \mathrm{p}<0.001\right.$; $\eta_{\mathrm{p}}{ }^{2}=0.018$ ). We observed significant interactions (year group $x$ quarter) for $4 \times 10 \mathrm{~m}$ shuttle run test $\left(\mathrm{F}_{6,3002}=5.38 ; \mathrm{p}<0.001\right.$; $\left.\eta_{p}{ }^{2}=0.011\right)$ and one-leg stance test $\left(F_{6,3002}=2.51 ; p=0.02\right.$; $\left.\eta_{\mathrm{p}}{ }^{2}=0.005\right)$. The pairwise comparisons are shown in Table 2 .

Figure 1 (handgrip strength test and standing long jump test) and Figure 2 (one-leg stance test, $4 \times 10 \mathrm{~m}$ shuttle run test and PREFIT $20 \mathrm{~m}$ shuttle run test) show the distribution of frequencies in percentage, from the fourth to the first quarters, in each year group, for the different intervals of the 5 fitness tests. In general, these figures show a higher percentage of preschoolers in interval 10 (i.e. the best performing preschoolers) among those who were born in quarter 1 , to the detriment to those who were born in the fourth quarter, for each age group, and for all tests evaluated. It can also be observed the contrary tendency, for those who were in interval 1.

\section{Discussion}

The main finding of this study is the existence of an effect of the relative age (i.e., RAE) over physical fitness, measured with the feasible and reliable PREFIT battery in children from 3 to 5 years old. In general, our data indicate that performance improves as the relative age increases. Despite the profuse amount of literature reporting the presence of RAE in physical fitness and sports selection, this is the first time that RAE has been reported in preschoolers ( 3 to 5 years old).

The multivariate analysis and its associated effect sizes indicate the presence of small to moderate RAE over the performance in the whole fitness battery, and that this effect differs depending on the year group as inferred from the double interaction between quarter of birth and year group. To the best of our knowledge, only the study by Cobley et al. compared RAE among the different year groups of their sample, with children between 11 and 14, years old, finding no double interaction between birthdate and year group (Cobley et al., 2008). The differences with our data are probably due to the different age ranges studied. In fact, in preschoolers, 3 months difference in birthdate time can account for up to $8 \%$ of their life, while in 11-year-olds it accounts for around $2 \%$. The latter has relevant implications for teachers and trainers as short-term programming is needed at preschool age to adapt to their specific fitness development.

Finding better performance as the age increases is to be expected, since older children have higher motor development and body growth than their younger counterparts (Wattie et al., 2015). In fact, recent works from our group developed with the same sample (Cadenas-Sanchez et al., 2019) and previous studies developed with children above 6 years, old and adolescents (Gulías-González et al., 2014; De Miguel-Etayo et al., 2014; Roriz De Oliveira et al., 2014) reported better values in the older children when compared by academic year group. However, the present study emphasizes the fact that in preschoolers within the same academic year group, in a time frame as short as a quarter (3 months), diverse physical performance can be found. This is in line with the idea of the cut-off dates as an important factor influencing the skills acquisition in several areas (physical, cognitive, self-efficacy, etc.) of children's development (Dutil et al., 2018). Therefore, compensation and individualization strategies for interventions, selections or evaluations should be 
Table 2. Results of the fitness performance tests across age groups.

\begin{tabular}{|c|c|c|c|c|c|c|c|c|c|}
\hline & & \multicolumn{2}{|c|}{$\begin{array}{c}\text { Quarter } 1 \\
\text { (Born from January to } \\
\text { March) }\end{array}$} & \multicolumn{2}{|c|}{$\begin{array}{c}\text { Quarter } 2 \\
\text { (Born from April to } \\
\text { June) }\end{array}$} & \multicolumn{2}{|c|}{$\begin{array}{c}\text { Quarter } 3 \\
\text { (Born from July to } \\
\text { September) }\end{array}$} & \multicolumn{2}{|c|}{$\begin{array}{c}\text { Quarter } 4 \\
\text { (Born from October to } \\
\text { December) }\end{array}$} \\
\hline & & Mean & SEM & Mean & SEM & Mean & SEM & Mean & SEM \\
\hline \multirow[t]{3}{*}{ Handgrip strength test $(\mathrm{kg})$} & 3 years & 5.57 & 0.12 & $5.07^{\mathrm{a}}$ & 0.12 & $4.68^{a}$ & 0.12 & $4.31^{\mathrm{ab}}$ & 0.13 \\
\hline & 4 years & $7.52^{*}$ & 0.11 & $7.22^{*}$ & 0.11 & $6.71^{a b_{*}}$ & 0.11 & $6.26^{\mathrm{abc} *}$ & 0.11 \\
\hline & 5 years & $9.68^{* \#}$ & 0.11 & $9.08^{\mathrm{a} * \#}$ & 0.11 & $8.38^{\mathrm{ab} * \#}$ & 0.11 & $7.92^{\mathrm{abc} * \#}$ & 0.11 \\
\hline \multirow[t]{3}{*}{ Standing long jump test $(\mathrm{cm})$} & 3 years & 60.44 & 1.07 & $55.71^{a}$ & 1.07 & $52.20^{\mathrm{a}}$ & 1.12 & $45.03^{a b c}$ & 1.15 \\
\hline & 4 years & $79.24^{*}$ & 0.98 & $77.37^{*}$ & 1.01 & $72.84^{\mathrm{ab}_{*}}$ & 1.02 & $68.52^{\mathrm{abc} c_{*}}$ & 0.98 \\
\hline & 5 years & $94.22^{* \#}$ & 1.01 & $90.05^{\mathrm{a} * \#}$ & 0.97 & $86.47^{a * \#}$ & 0.99 & $84.18^{\mathrm{ab} * \#}$ & 0.99 \\
\hline \multirow{3}{*}{ One-leg stance test (sec) } & 3 years & 6.52 & 1.03 & 5.55 & 1.04 & 4.49 & 1.08 & 4.04 & 1.11 \\
\hline & 4 years & $15.73^{*}$ & 0.95 & $11.64^{\mathrm{a} *}$ & 0.98 & $11.88^{\mathrm{a} *}$ & 0.99 & $9.47^{a *}$ & 0.95 \\
\hline & 5 years & $26.01^{* \#}$ & 0.98 & $25.66^{* \#}$ & 0.94 & $20.18^{\mathrm{ab} * \#}$ & 0.96 & $19.50^{\mathrm{ab} * \#}$ & 0.96 \\
\hline \multirow{3}{*}{$4 \times{ }_{\lambda} 10 \mathrm{~m}$ shuttle run test $(\mathrm{s})$} & 3 years & 18.40 & 0.12 & $18.89^{\mathrm{a}}$ & 0.12 & $19.49^{\mathrm{ab}}$ & 0.12 & $20.29^{\mathrm{abc}}$ & 0.12 \\
\hline & 4 years & $16.05^{*}$ & 0.11 & $16.33^{*}$ & 0.11 & $16.56^{\mathrm{a} *}$ & 0.11 & $17.27^{\mathrm{abc} *}$ & 0.11 \\
\hline & 5 years & $14.76^{* \#}$ & 0.11 & $14.95^{* \#}$ & 0.11 & $15.31^{\mathrm{a} * \#}$ & 0.11 & $15.48^{\mathrm{ab} * \#}$ & 0.11 \\
\hline \multirow[t]{3}{*}{ PREFIT 20 m shuttle run test (laps) } & 3 years & 15.16 & 0.64 & 12.98 & 0.64 & $10.57^{\mathrm{a}}$ & 0.67 & $9.75^{\mathrm{ab}}$ & 0.69 \\
\hline & 4 years & $22.45^{*}$ & 0.59 & $20.51^{*}$ & 0.61 & $19.18^{a_{*}}$ & 0.62 & $17.11^{a b_{*}}$ & 0.59 \\
\hline & 5 years & $28.76^{* \#}$ & 0.61 & $27.14^{* \#}$ & 0.59 & $24.93^{\mathrm{ab} * \#}$ & 0.60 & $24.44^{\mathrm{ab} * \#}$ & 0.59 \\
\hline
\end{tabular}

Data are presented as mean \pm standard error of mean (SEM); ${ }^{a} p<0,05$ different to quarter $1 ;{ }^{b} p<0,05$ different to quarter $2 ;{ }^{c} p<0,05$ different to quarter $3 ;{ }^{*} p<0.05$ different to 3 years; and ${ }^{\#} p<0.05$ different to 4 years.
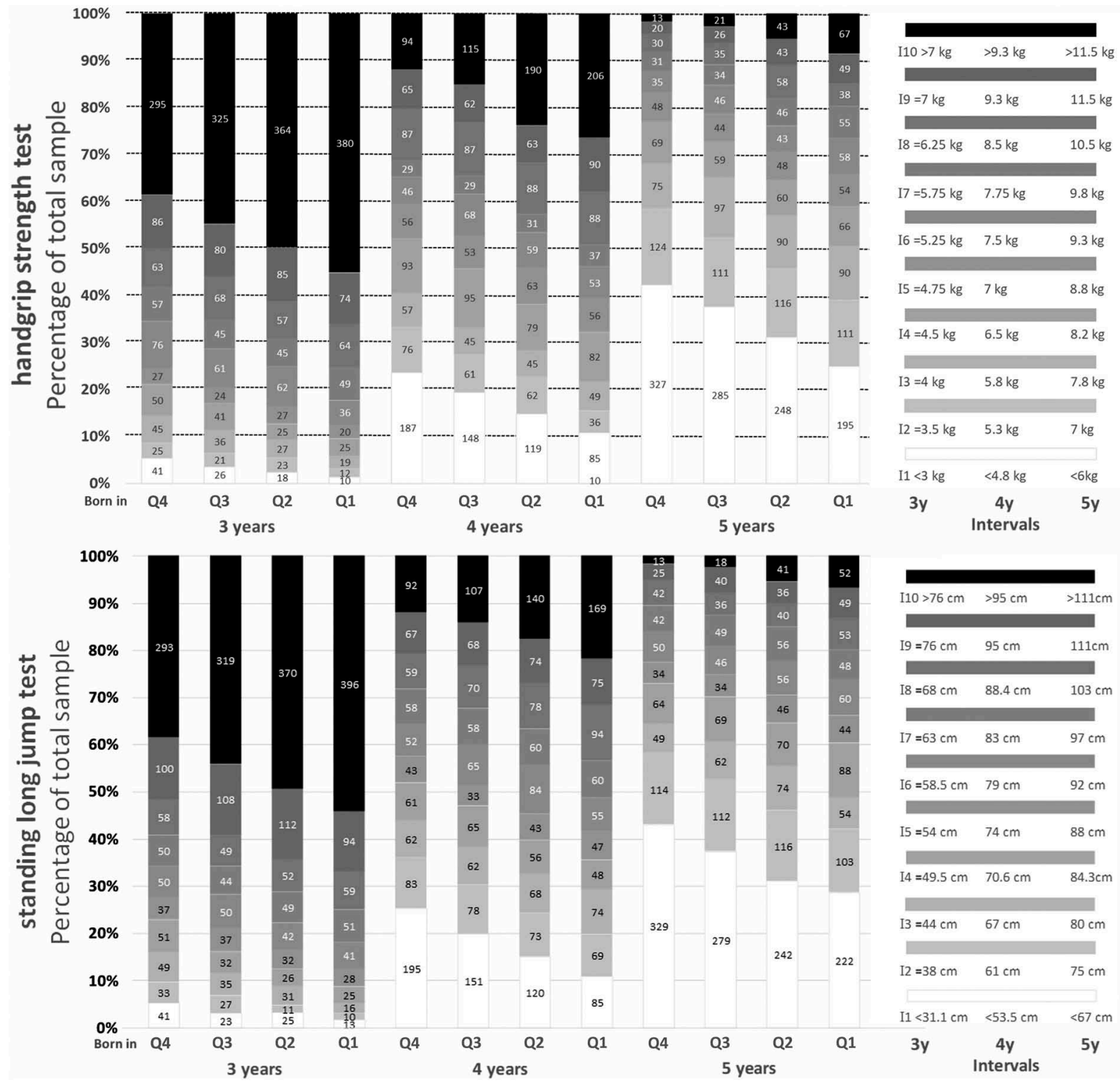

Figure 1. Intervals of performance for each quarter of age in 3-, 4- and 5-years preschoolers, and frequencies of preschoolers in each interval for the handgrip strength test and the standing long jump test. Limit values for intervals are shown on the right. Numbers inside the bars represent the number of preschoolers within each interval, and frequency percentages are represented in the left axis. Q1 = born between January and March (i.e. the eldest within the age group); Q2 = born between April and June; Q3 = born between July and September; Q4 = born between October and December (i.e. the youngest within the age group). 

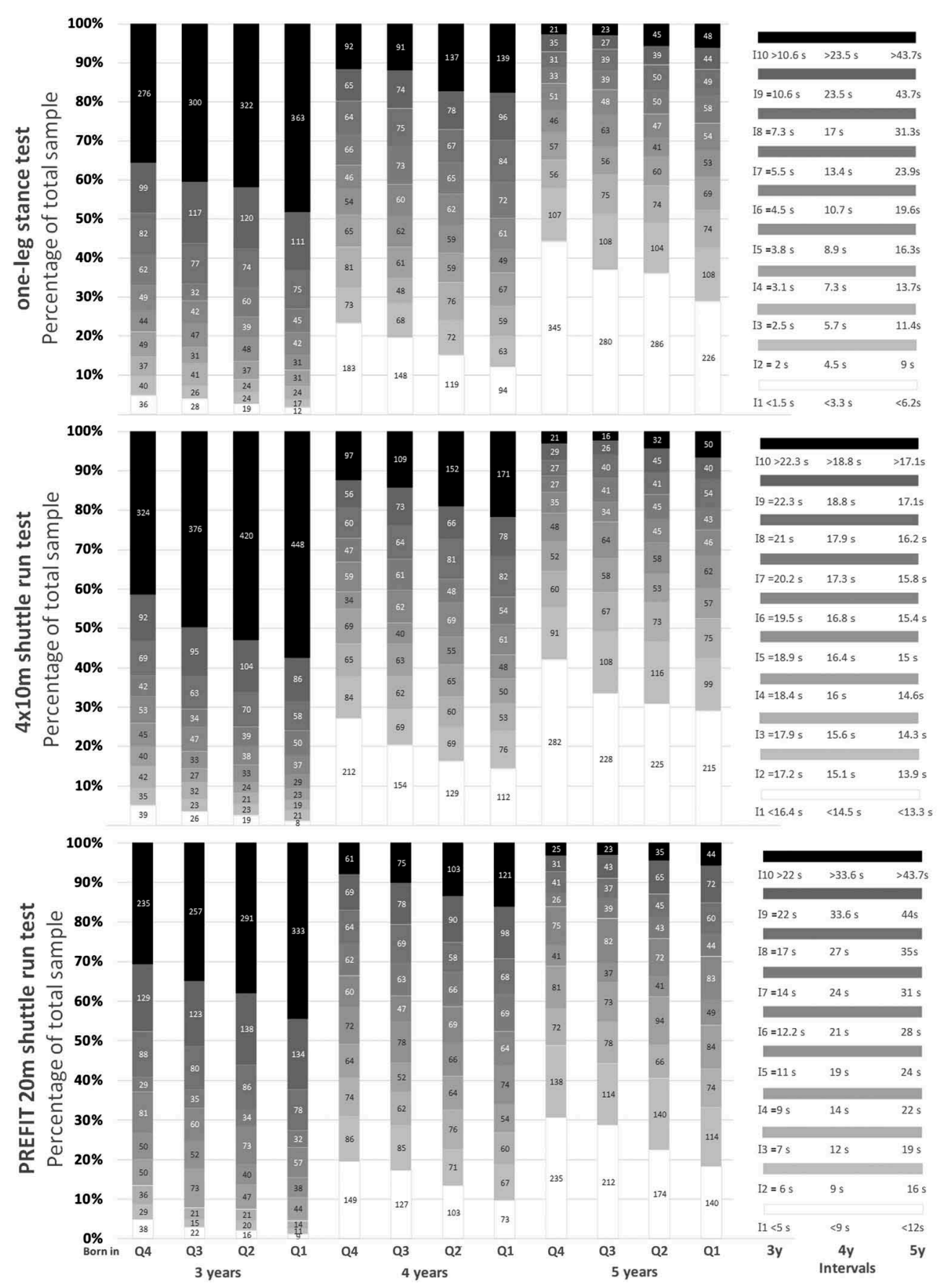

Figure 2. Intervals of performance for each quarter of age in 3-, 4- and 5-years preschoolers, and frequencies of preschoolers in each interval for the one-leg stance test, the $4 \times 10 \mathrm{~m}$ shuttle run test and the PREFIT $20 \mathrm{~m}$ shuttle run test. Limit values for intervals are shown on the right. Numbers inside the bars represent the number of preschoolers within each interval, and frequency percentages are represented in the left axis. Q1 = born between January and March (i.e. . the eldest within the age group); Q2 = born between April and June; Q3 = born between July and September; Q4 = born between October and December (i.e. the youngest within the age group).

380 addressed within the same academic year not only in elementary or secondary years, as it has already been recommended (Mann \& van Ginneken, 2017; Philippaerts et al., 2006; Wattie et al., 2015), but also in preschool children. The proposed strategies that might be implemented in schools could be applying correc-

385 tive mathematical adjustments to the results (for example, multiply the race time, or any other mark, by a corrective factor) (Romann et al., 2015); grouping students based on their biological age instead on their chronological age (Albuquerque et al., 2012; Hurley et al., 2001; Musch \& Grondin, 2001); or make the teachers aware in some way about the relative age of the students (e.g., by numbering their shirts), so that they keep this effect in mind when grading (Mann \& van Ginneken, 2017). Other solutions seen in previous investigations come from sports contexts and may be difficult to apply in educational centres, such as shifting selection dates or imposing restrictions on the age in which players were invited to attend selection events (Haycraft et al., 2018).

Our results show a progressive linear rising of physical fitness across the quarters for most of the tests performed. In this 
400 regard, we find contradictory results in literature, reporting either a well-fitted linear improvement as relative age advances (Bell et al., 1997) or non-linear changes in function of relative age (Cobley et al., 2008). However, the lack of progressive increment in performance seen by Cobley et al., as they admitted in their work, could be due to the lower sample size, the proximity to puberty of their sample and hence the biological maturity variation, and also to the heterogeneity of experience and practice in physical activities of their sample. In our results, the only test that seems not to follow this behaviour, at some point is the balance test, where a double interaction (year groups $\times$ quarter) was found in the between-participants effects test. This double interaction may probably appear due to the absence of differences among quarters within the 3years group, and the different progression seen in 4-year- and

415 5-year-old group performances. In a previous study (CadenasSanchez, Martinez-Tellez et al., 2016) this test showed poorer reliability when more than 2 measurements separated by a period of time are made (for example, in pre-post assessments), and the variability error increased as the performance in the test was higher; so, it may be reasonable that the lowest error exists in the group in which we did not observe differences among quarters. Maybe the sensibility of the test is not enough for reporting the difference in performance within the 3-yearold children; or perhaps the differences in balance development of this physical ability between 3-year-old and 4-year-old preschoolers (Assaiante, 1998) may interfere in the results of the test, since significant differences among quarters started to appear at the end of age 4. Although the application of this specific result regarding the balance test could be limited due to the reliability of the test, we prefer showing the results in order to help professionals, researchers and future studies, providing an initial reference. As far as we are aware, no previous studies analysing RAE included static balance as a main measurement, and therefore more investigation is needed before assuming any hypothesis in this regard.

The other physical test showing a double interaction (year group $x_{\lambda}$ quarter) in the analysis of variance was the $4 \times 10 \mathrm{~m}$ shuttle run test. However, in this case, the differences among each year group for RAE are not as evident as in the balance test. An attenuation in the magnitude of the change was perceived between quarters as the year group was older, as well as less significant differences among quarters, meaning that the changes among quarters in 3 years old are more pronounced than in 4 and 5 years old, and the same happens when comparing 4 vs 5 years old. To the best of our knowledge, only 1 previous work measured agility in preschoolers, but with a $10 \times 5 \mathrm{~m}$ shuttle run test and not analysing differences among age groups (Silva-Santos et al., 2017). Moreover, none of the works examining RAE and physical performance assess agility with the $4 \times 10 \mathrm{~m}$ shuttle run test. Therefore, it is not possible to compare our results with others to confirm the different effect of relative age in each year group.

For the remaining univariance tests (i.e. handgrip strength test, standing long jump test and the PREFIT 20 m shuttle run test) no interaction was observed. The analysis showed main effects for year group and for quarter of birth. This implies that the performance improves as the age group progresses, but the effect of relative age is consistent among these different year groups, and that similar performance changes among children born in different quarters but within the same year, are expected throughout all the preschool stage. The presence of RAE in preschoolers supports most of the works performed in older samples and using similar tests as those present in the PREFIT battery, such as 20 m shuttle run test (Nakata et al., 2017; Roberts et al., 2012; Sandercock et al., 2014, 2013), handgrip strength test (Nakata et al., 2017; Sandercock et al., 2014, 2013; Ulbricht et al., 2015) or standing long jump test (Nakata et al., 2017). However, none of these studies analysed the interaction between year group and quarter. Therefore, we cannot infer if the magnitude of the relative age effect varies over the years in children and adolescents, as we have observed in preschoolers with our data and the double interaction reported.

Regarding the frequency distribution in the calculated intervals, analysis that we performed to complement the MANOVA, different nuances of the results can be observed. In general, the highest intervals (i.e., those reflecting better performance) and especially the 10th, increase as the relative age increase, while the lowest intervals, primarily the $1 \mathrm{st}$, decrease. That is, the relatively older the preschoolers are, the more frequently they get results close to the maximum value recorded for their year group. Although in most cases this behaviour is progressive from quarter to quarter, there are cases in which a small "standstill" is observed, where the frequency is similar between 2consecutive quarters. This appears to be more common in the 5-year age group, such as in the balance test (i.e. quarter 1 is similar to quarter 2 , and quarter 3 to quarter 4 ), or the PREFIT $20 \mathrm{~m}$ shuttle run test (quarter 1 is similar to quarter 2). Comparing the frequencies year by year, we can see, in all the tests, how within the 3-years group there are more children close to their maximal value in 3-years, and in the 5-years group, more children are near the lowest value for 5-years. It seems that the relative performance of preschoolers falls when they progress to the next grade, suggesting that the performance of preschoolers drops as they move up the school year. Physical growth and experience could underlie these observations: growth may be the limiting factor for performance in 3years, while in 5-years, the range of physical growth is wider (Sánchez González et al., 2011; Tanner \& Whitehouse, 1976) and experience of the least and most active could influence these results.

In respect to the influence of gender, and going back to the results derived from the MANOVA test, no triple interaction (quarter $x_{\lambda}$ sex $x_{\lambda}$ year group) and no double interaction between sex and birthdate were seen in our multivariate analysis, suggesting that RAE over performance in the PREFIT battery was similar between genders. This is in contrast with the results by Sandercock et al. (2013) and Roberts and Fairclough (2012), since they reported much greater evidence of RAE in male than in female participants. However, it is important to highlight that the sample in the above-mentioned studies was much older than our sample, 10 to 16 years old. In fact, Nakata et al. found similar RAE in physical fitness data of both genders in children from 7 to 10 , but a more evident RAE for boys than girls in adolescents (i.e. 11-15 years old), supporting the idea of the appearance of gender differences for RAE only in older groups (Nakata et al., 2017). The fact that relative age has a similar effect in both genders during the pre-scholar period and elementary 
school, but a different effect later in life could reflect the progressive appearance of social/environmental factors that have been proposed to influence RAE in the largest mode (Hancock et al., 2013), also reflecting that these factors could be different for boys and girls.

Finally, the statistical analysis revealed small effect sizes for the multivariate analysis, as well as for the one-leg stance test, the standing long jump test and the PREFIT $20 \mathrm{~m}$ shuttle run test. Moderate values were observed for the handgrip strength test and the $4 \times 10 \mathrm{~m}$ shuttle run test. To the best of our knowledge, we cannot compare these small to moderate values with previous studies. The only work detailing the effect size values is the meta-analysis performed by Cobley et al. (2009), who detected small significant effects across age categories. However, they analysed RAE as the different births frequencies among quarters, while we analyse RAE as the differences in fitness performance among quarters. Although both are consequences of the relative age, and in both cases, most of the effects detected were small but still significant, the comparison may not be correct. Therefore, more research detailing the effect size of RAE in fitness performance is needed to be able to quantify the amount of effect of the relative age.

Several approaches have been proposed for attenuating RAE in physical education and sports contexts (Cobley et al., 2009; Mann \& van Ginneken, 2017), but preschoolers are unlikely to be scouted and recruited in any sport. As we said above in this context the most reasonable strategies seem to aware teachers and coaches regarding the existence of diverse motor attainments within the same year group (Cobley et al., 2009; Philippaerts et al., 2006), applying corrective adjustments (Romann et al., 2015); or grouping students based on their biological age (Albuquerque et al., 2012; Hurley et al., 2001; Musch \& Grondin, 2001). Since the younger pupils have the potential to achieve the same level as their older peers in the future (Bell \& Daniels, 1990), adults should consider the existence of this effect and compensate it in their interaction with children, individualizing the demands or goals in each discipline. These compensation approaches are especially important if we consider that many of these children will go through future sports selection and physical activity participation processes; knowing that RAE is present even before the period of sports selection, it is important to attenuate this effect already

560 at this early stage, controlling and being aware of the constraints (individual, task and environmental) and their relations, which influence the presence of RAE (Wattie et al., 2015).

Regarding limitations, we are aware that the study sample may not be representative of Spain since we did not consider the school type characteristics, and the geographical distribution was not random. However, we selected the sample to be as representative of the average level of demography, cultural, social and economic markers as possible. Therefore, although these results may not be applicable to all of the Spanish settings, and might need more future studies, they could be applied to most of them. Another limitation of the present study is that we did not analyse factors that could explain RAE at this age, such as attendance at sports/physical exercise activities (i.e. supervised activities), skeletal age or anthropometric parameters, or measurement of social/behavioural factors such as the Mathew effect (the best are provided with more opportunities to practice), Pygmalion effect (the greater the expectation placed on an individual, the greater the result that individual will attain) or Galatea effect (once expectations are placed upon an individual, that individual typically acts congruently with those expectations) which have been proposed to influence RAE (Hancock et al., 2013). However, to the best of our knowledge, this is the first study to report the existence of RAE at as early as the preschool stage, using a statistically powerful sample size and a reliable and valid test for this particular sample.

\section{Acknowledgments}

The authors thank the participation of the preschoolers participating in this study, as well as their parents, teachers and the rest of the school's employees.

\section{Disclosure statement}

No potential conflict of interest was reported by the authors.

\section{Funding}

CC-S is supported by Spanish Ministry of Science, Innovation and Universities [FJC2018-037925-I]. EGA is supported by grants from the Spanish Ministry of Science and Innovation (RYC-2014-16390). JM-G is supported by the Spanish Ministry of Education, Culture and Sport (FPU14/06837). In addition, this study was further supported by the University of Zaragoza (JIUZ-2014-BIO-08), and by the University of Granada, Plan Propio de Investigación 2016, Excellence actions: Units of Excellence; Unit of Excellence on Exercise and Health (UCEES). Additional funding from the SAMID III network, RETICS, funded by the PN I+D+I 20172021 (Spain), ISCIII- Sub-Directorate General for Research Assessment and Promotion, the European Regional Development Fund (ERDF) (Ref. RD16/ 0022), the EXERNET Research Network on Exercise and Health in Special Populations (DEP2005-00046/ACTI).

\section{ORCID}

Julio Conde-Caveda (iD) http://orcid.org/0000-0002-2788-231X Germán Vicente-Rodríguez (iD http://orcid.org/0000-0002-4303-4097 Pedro J. Benito (D) http://orcid.org/0000-0002-1631-8182

\section{References}

Albuquerque, M. R., Lage, G. M., da Costa, V. T., Ferreira, R. M., Penna, E. M., Moraes, L. C., \& Malloy-Diniz, L. F. (2012). Relative age effect in Olympic Taekwondo athletes. Perceptual and Motor Skills, 114(2), 461-468. https://doi.org/10.2466/05.25.PMS.114.2.461-468

Andronikos, G., Elumaro, A. I., Westbury, T., \& Martindale, R. J. J. J. (2016). Relative age effect: Implications for effective practice. Journal of Sports Sciences, 34(12), 1124-1131. https://doi.org/10.1080/02640414.2015. 1093647

Assaiante, C. (1998). Development of locomotor balance control in healthy children. Neuroscience \& Biobehavioral Reviews, 22(4), 527-532. https:// doi.org/10.1016/S0149-7634(97)00040-7

Baker, J., Schorer, J., Cobley, S., Schimmer, G., \& Wattie, N. (2009). Circumstantial development and athletic excellence: The role of date of birth and birthplace. European Journal of Sport Science, 9(6), 329-339. https://doi.org/10.1080/17461390902933812

Bedard, K., \& Dhuey, E. (2006). The persistence of early childhood maturity: International evidence of long-run age effects. The Quarterly Journal of Economics, 121, 1437-1472. 
Bell, J. F., \& Daniels, S. (1990). Are Summer-born children disadvantaged? The birthdate effect in education. Oxford Review of Education, 16(1), 6780. https://doi.org/10.1080/0305498900160106

Bell, J. F., Massey, A., \& Dexter, T. (1997). Birthdate and ratings of sporting achievement: Analysis of physical education GCSE results. European Journal of Physical Education, 2(2), 160-166. https://doi.org/10.1080/ 1740898970020203

Birch, S., Cummings, L., Oxford, S. W., \& Duncan, M. J. (2016). Examining relative age effects in fundamental skill proficiency in british children Aged 6-11 years. Journal of Strength and Conditioning Research, 30(10), 2809-2815. https://doi.org/10.1519/JSC.0000000000000526

640 Brazo-Sayavera, J., Martínez-Valencia, M. A., Müller, L., Andronikos, G., \& Martindale, R. J. J. (2017). Identifying talented track and field athletes: The impact of relative age effect on selection to the Spanish National Athletics Federation training camps. Journal of Sports Sciences, 35(22), 2172-2178. https://doi.org/10.1080/02640414.2016.1260151

645 Cadenas-Sánchez, C., Alcántara-Moral, F., Sánchez-Delgado, G., MoraGonzález, J., Martínez-Téllez, B., Herrador-Colmenero, M., JiménezPavón, D., Femia, P., Ruiz, J. R., \& Ortega, F. B. (2014). Assessment of cardiorespiratory fitness in preschool children: Adaptation of the 20 metres shuttle run test. Nutricion hospitalaria, 30(6), 1333-1343. https:// doi.org/10.3305/nh.2014.30.6.7859

Cadenas-Sanchez, C., Intemann, T., Labayen, I., Peinado, A. B., Vidal-Conti, J., Sanchis-Moysi, J., Moliner-Urdiales, D., Rodriguez Perez, M. A., Cañete Garcia-Prieto, J., Del Rosario Fernández-Santos, J., Martinez-Tellez, B., Vicente-Rodríguez, G., Löf, M., Ruiz, J. R., \& Ortega, F. B. (2019). Physical fitness reference standards for preschool children: The PREFIT project. Journal of Science and Medicine in Sport, 22(4), 430-437. https://doi.org/ 10.1016/j.jsams.2018.09.227

Cadenas-Sanchez, C., Martinez-Tellez, B., Sanchez-Delgado, G., MoraGonzalez, J., Castro-Piñero, J., Löf, M., Ruiz, J. R., \& Ortega, F. B. (2016). Assessing physical fitness in preschool children: Feasibility, reliability and practical recommendations for the PREFIT battery. Journal of Science and Medicine in Sport, 19(11), 910-915. https://doi.org/10.1016/ j.jsams.2016.02.003

Cadenas-Sanchez, C., Sanchez-Delgado, G., Martinez-Tellez, B., MoraGonzalez, J., Löf, M., España-Romero, V., Ruiz, J. R., \& Ortega, F. B. (2016). Reliability and validity of different models of TKK hand dynamometers. American Journal of Occupational Therapy, 70(4), 7004300010. https://doi.org/10.5014/ajot.2016.019117

Cobley, S., Abraham, C., \& Baker, J. (2008). Relative age effects on physical education attainment and school sport representation. Physical Education \& Sport Pedagogy, 13(3), 267-276. https://doi.org/10.1080/ 17408980701711983

Cobley, S., Baker, J., Wattie, N., \& McKenna, J. (2009). Annual age-grouping and athlete development: A meta-analytical review of relative age effects in sport. Sports Medicine, 39(3), 235-256. https://doi.org/10. 2165/00007256-200939030-00005

Cohen, J. (1988). Statistical power analysis for the behavioral sciences. Routledge.

Dalen, T., Ingvaldsen, R. P., Roaas, T. V., Pedersen, A. V., Steen, I., \& Aune, T. K. (2017). The impact of physical growth and relative age effect on assessment in physical education. European Journal of Sport Science, 17(4), 482487. https://doi.org/10.1080/17461391.2016.1268651

De Miguel-Etayo, P., Gracia-Marco, L., Ortega, F. B., Intemann, T., Foraita, R., Ler, L., Oja, L., Barba, G., Michels, N., Tornaritis, M., Molnár, D., Pitsiladis, Y., Ahrens, W., Moreno, L. A., \& IDEFICS consortium. (2014). Physical fitness reference standards in European children: The IDEFICS study International Journal of Obesity, 38(S2), S57-S66. https://doi.org/10. 1038/ijo.2014.136

Dutil, C., Tremblay, M. S., Longmuir, P. E., Barnes, J. D., Belanger, K., \& Chaput, J.-P. (2018). Influence of the relative age effect on children's scores obtained from the Canadian assessment of physical literacy. BMC Public Health, 18(S2), 1040. https://doi.org/10.1186/s12889-018-5895-6

Furley, P., \& Memmert, D. (2016). Coaches' implicit associations between size and giftedness: Implications for the relative age effect. Journal of Sports Sciences, 34(5), 459-466. https://doi.org/10.1080/02640414.2015.1061198

Gledhill, J., Ford, T., \& Goodman, R. (2002). Does season of birth matter? The relationship between age within the school year (Season of Birth) and educational difficulties among a representative general population sample of children and adolescents (aged 5-15) in Great Britain. Research in Education, 68(1), 41-47. https://doi.org/10.7227/RIE.68.4

Gulías-González, R., Sánchez-López, M., Olivas-Bravo, Á., Solera-Martínez, M., \& Martínez-Vizcaíno, V. (2014). Physical fitness in Spanish schoolchildren aged 6-12 years: Reference values of the battery EUROFIT and associated cardiovascular risk. Journal of School Health, 84(10), 625-635. https://doi.org/10.1111/josh.12192

Hancock, D. J., Adler, A. L., \& Côté, J. (2013). A proposed theoretical model to explain relative age effects in sport. European Journal of Sport Science, 13 (6), 630-637. https://doi.org/10.1080/17461391.2013.775352

Haycraft, J. A. Z., Kovalchik, S., Pyne, D. B., Larkin, P., \& Robertson, S. (2018). The influence of age-policy changes on the relative age effect across the Australian Rules football talent pathway. Journal of Science and Medicine in Sport, 21(10), 1106-1111. https://doi.org/10.1016/j.jsams.2018.03.008

Hurley, W., Lior, D., \& Tracze, S. (2001). A proposal to reduce the age discrimination in Canadian Minor Hockey. Canadian Public Policy / Analyse de Politiques, 27(1), 65. https://doi.org/10.2307/3552374

Kearney, P. E., Hayes, P. R., \& Nevill, A. (2018). Faster, higher, stronger, older: Relative age effects are most influential during the youngest age grade of track and field athletics in the United Kingdom. Journal of Sports Sciences, 36(20), 2282-2288. https://doi.org/10.1080/02640414.2018. 1449093

Léger, L. A., Mercier, D., Gadoury, C., \& Lambert, J. (1988). The multistage 20 metre shuttle run test for aerobic fitness. Journal of Sports Sciences, 6(2), 93-101. https://doi.org/10.1080/02640418808729800

Mann, D. L., \& van Ginneken, P. J. M. A. (2017). Age-ordered shirt numbering reduces the selection bias associated with the relative age effect. Journal of Sports Sciences, 35(8), 784-790. https://doi.org/10.1080/02640414. 2016.1189588

Müller, L., Hildebrandt, C., \& Raschner, C. (2015). The relative age effect and the influence on performance in youth alpine ski racing. Journal of Sports science \& Medicine, 14(1), 16-22.

Musch, J., \& Grondin, S. (2001). Unequal competition as an impediment to personal development: A review of the relative age effect in sport. Developmental Review, 21(2), 147-167. https://doi.org/10.1006/drev. 2000.0516

Nakata, H., Akido, M., Naruse, K., \& Fujiwara, M. (2017). Relative age effect in physical fitness among elementary and junior high school students. Perceptual and Motor Skills, 124(5), 900-911. https://doi.org/10.1177/ 0031512517722284

Ortega, F. B., Cadenas-Sánchez, C., Sánchez-Delgado, G., Mora-González, J., Martínez-Téllez, B., Artero, E. G., Castro-Piñero, J., Labayen, I., Chillón, P., Löf, M., Ruiz, J. R., et al (2015). Systematic review and proposal of a fieldbased physical fitness-test battery in preschool children: The PREFIT battery. Sports Medicine, 45(4), 533-555. https://doi.org/10.1007/ s40279-014-0281-8

Palou, P., Muntaner-Mas, A., Cantallops, J., Borràs, P. A., Labayen, I., JiménezPavón, D., Dorado García, C., Moliner-Urdiales, D., Rodríguez Pérez, M. A., Rojo-Tirado, M. A., Cadenas-Sanchez, C., Ortega, F. B., \& Vidal-Conti, J. (2019). A single question of parent-reported physical activity levels estimates objectively measured physical fitness and body composition in preschool children: The PREFIT project. Frontiers in Psychology, 10, 1585. https://doi.org/10.3389/fpsyg.2019.01585

Philippaerts, R. M., Vaeyens, R., Janssens, M., Van Renterghem, B., Matthys, D., Craen, R., Bourgois, J., Vrijens, J., Beunen, G., \& Malina, R. M. (2006). The relationship between peak height velocity and physical performance in youth soccer players. Journal of Sports Sciences, 24(3), 221 230. https://doi.org/10.1080/02640410500189371

Roberts, S. J., Boddy, L. M., Fairclough, S. J., \& Stratton, G. (2012). The influence of relative age effects on the cardiorespiratory fitness levels of children age 9 to 10 and 11 to 12 years of age. Pediatric Exercise Science, 24(1), 72-83. https://doi.org/10.1123/pes.24.1.72

Roberts, S. J., \& Fairclough, S. J. (2012). The influence of relative age effect in the assessment of high school students in physical education in the United Kingdom. Journal of Teaching in Physical Education, 31(1), 56-70. https://doi.org/10.1123/jtpe.31.1.56

Romann, M., Cobley, S., \& Gonzalez, G. E. (2015). Relative age effects in athletic sprinting and corrective adjustments as a solution for their removal (GE Gonzalez, Ed.). PloS One, 10(4), e0122988. https://doi.org/ 10.1371/journal.pone. 0122988 
Roriz De Oliveira, M. S., Seabra, A., Freitas, D., Eisenmann, J. C., \& Maia, J. (2014). Physical fitness percentile charts for children aged 6-10 from Portugal. The Journal of Sports medicine and Physical Fitness, 54(6), 780-792.

Sánchez González, E., Carrascosa Lezcano, A., Fernández García, J. M., Ferrández Longás, A., López de Lara, D., \& López-Siguero, J. P. (2011). Estudios españoles de crecimiento: Situación actual, utilidad y recomendaciones de uso. Anales De Pediatría, 74(3), 193.e1-193.e16. https://doi. org/10.1016/j.anpedi.2010.10.005

Sanchez-Delgado, G., Cadenas-Sanchez, C., Mora-Gonzalez, J., MartinezTellez, B., Chillón, P., Löf, M., Ortega, F. B., \& Ruiz, J. R. (2015). Assessment of handgrip strength in preschool children aged 3 to 5 years. Journal of Hand Surgery (European Volume), 40(9), 966-972. https://doi.org/10.1177/1753193415592328

Sandercock, G. R. H., Ogunleye, A. A., Parry, D. A., Cohen, D. D., Taylor, M. J. D., \& Voss, C. (2014). Athletic performance and birth month: Is the relative age effect more than just selection bias? International Journal of Sports Medicine, 35(12), 1017-1023. https://doi.org/10.1055/s-00341368725

Sandercock, G. R. H., Taylor, M. J., Voss, C., Ogunleye, A. A., Cohen, D. D., \& Parry, D. A. (2013). Quantification of the relative age effect in three indices of physical performance. Journal of Strength and Conditioning Research, 27(12), 3293-3299. https://doi.org/10.1519/JSC. 0b013e318291b28d
Silva-Santos, S., Santos, A., Vale, S., \& Mota, J. (2017). Motor fitness and preschooler children obesity status. Journal of Sports Sciences, 35(17), 1704-1708. https://doi.org/10.1080/02640414.2016.1232486

Smith, J. J., Eather, N., Morgan, P. J., Plotnikoff, R. C., Faigenbaum, A. D., \& Lubans, D. R. (2014). The health benefits of muscular fitness for children and adolescents: A systematic review and meta-analysis. Sports Medicine, 44(9), 1209-1223. https://doi.org/10.1007/s40279-014-0196-4

Tanner, J. M., \& Whitehouse, R. H. (1976). Clinical longitudinal standards for height, weight, height velocity, weight velocity, and stages of puberty. Archives of Disease in Childhood, 51(3), 170-179. https://doi.org/10.1136/ adc.51.3.170

Ulbricht, A., Fernandez-Fernandez, J., Mendez-villanueva, A., \& Ferrauti, A. (2015). The relative age effect and physical fitness characteristics in German male tennis players. Journal of Sports science \& Medicine, 14(3), 634-642.

Wattie, N., Schorer, J., \& Baker, J. (2015). The relative age effect in sport: A developmental systems model. Sports Medicine, 45(1), 83-94. https://doi. org/10.1007/s40279-014-0248-9

Wienen, A. W., Batstra, L., Thoutenhoofd, E., de Jonge, P., Bos, E. H., \& Neuenschwander, R. (2018). Teachers' perceptions of behavioral problems in Dutch primary education pupils: The role of relative age. ( $R$ Neuenschwander, Ed.). PLoS One, 13(10), e0204718. https://doi.org/10. 1371/journal.pone.0204718 